\section{Expansion of metallic mesh stent hole using a Soehendra stent retriever in multiple stenting of biliary hilar obstruction}
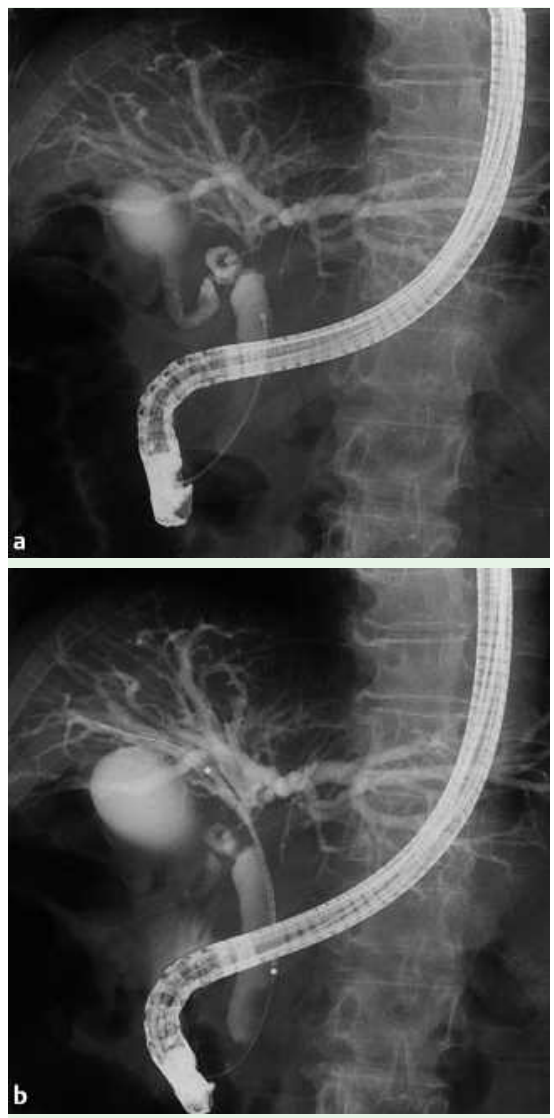

Fig. 1 a Cholangiogram showing a Bismuth type III hilar stricture. b A metallic mesh stent was placed in the right biliary tree.

A malignant hilar biliary stricture is usually unresectable at the time of diagnosis and requires multiple biliary stentings. Metallic mesh stents remain patent for a relatively long time in the biliary stricture compared to tube stents [1]. However, employing multiple metallic mesh stents is sometimes very difficult because of their small lumen, which impedes the delivery of a catheter. The Soehendra stent retriever (Soehendra SR; Wilson-Cook Medical Inc., WinstonSalem, North Carolina, USA) is useful for dilating a stenosed biliary or pancreatic duct [2-4]. We used it to expand the mesh holes in metallic mesh stents placed in patients with malignant biliary hilar stricture who were undergoing multiple stenting.
Fig. 2 a A Soehendra stent retriever was advanced along the guide wire to expand the mesh holes of the first metallic mesh stent. b A metallic mesh stent delivery catheter was then easily introduced into the left biliary tree. c Multiple stenting was successfully accomplished.
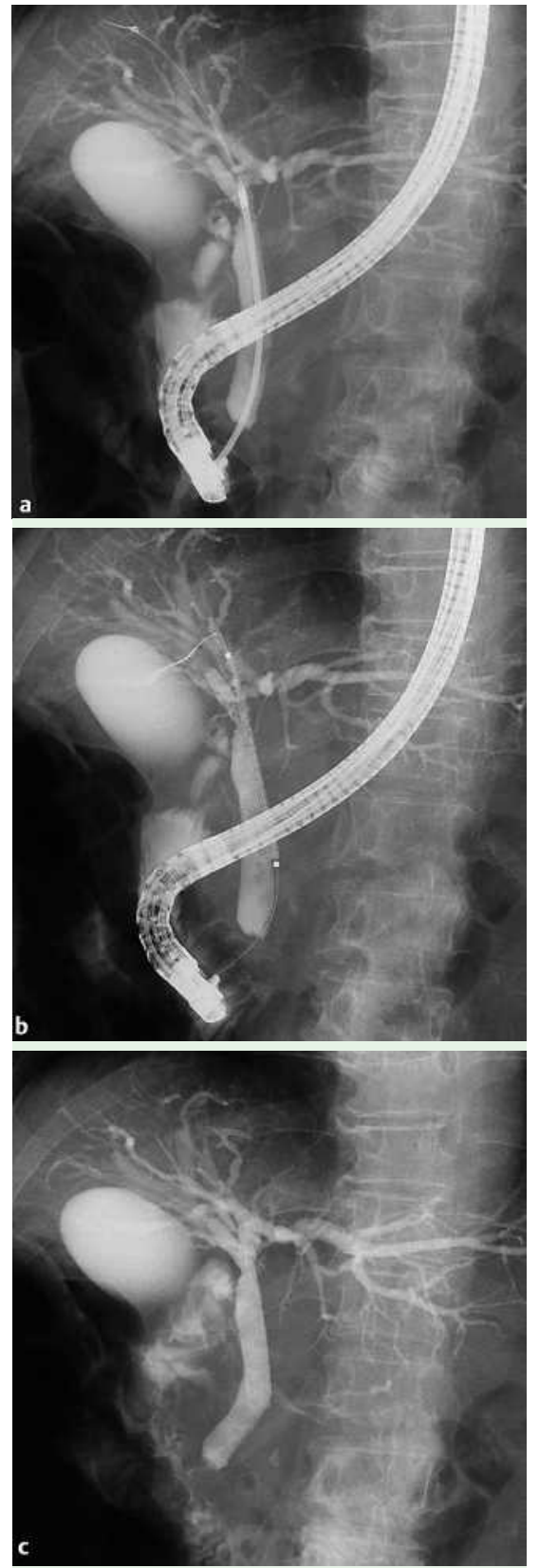

\section{T. Hara ${ }^{1}$, T. Yamaguchi ${ }^{1}$, K. Sudo ${ }^{1}$, K. Nakamura', T. Denda ${ }^{1}$, T. Ishihara ${ }^{2}$, O. Yokosuka², T. Kouzu ${ }^{3}$}

1 Department of Gastroenterology, Chiba Cancer Center, Chiba, Japan

2 Department of Medicine and Clinical Oncology, Graduate School of Medicine, Chiba University, Chiba, Japan

Department of Endoscopic Diagnostics and Therapeutics, Graduate School of Medicine, Chiba University, Chiba, Japan
We used the retriever in three patients giogram of a patient with a Bismuth type III stricture. A guide wire was negotiated mesh stent inserted (JoStent SelfX stent; Vascular Devices, Redwood City, ond guide wire was negotiated into the left biliary tree through a mesh hole in using dilation catheters, it was not possibe to insert them into the left biliary tree stents. We therefore introduced a Soehendra SR and advanced it along the wire, turning it clockwise to allow gage the mesh and expand the stent hole ( Fig.2a). After expansion, a metallic mesh stent delivery catheter was easily ( Fig. 2b) and multiple stenting was achieved ( $\bullet$ Fig. 2c). We successfully carmed stents in two other patients and relevant complications were encountered. Our results indicate that the Soerequiring multiple stenting with metallic mesh stents.

\section{Endoscopy_UCTN_Code_TTT_1AR_2AZ}




\section{References}

1 Kaassis M, Boyer J, Dumas R et al. Plastic or metal stents for malignant stricture of the common bile duct? Results of a randomized prospective study. Gastrointest Endosc 2003; 57: $178-182$

2 Soehendra N, Mayde A, Eckmann B et al. A new technique for replacing an obstructed biliary endoprothesis. Endoscopy 1990; 22: $271-272$

3 Faigel DO, Ginsberg GG, Kochman ML. Innovative use of the Soehendra stent retriever for biliary stricture recannalization. Gastrointest Endosc 1996; 44: 635

4 Brand B, Thonke S, Obytz KF et al. Stent retriever for dilation of pancreatic and bile duct strictures. Endoscopy 1999; 31: $142-$ 145

\section{Bibliography}

DOI $10.1055 / \mathrm{s}-2007-995769$

Endoscopy 2008; 40: E147-E148

(c) Georg Thieme Verlag KG Stuttgart · New York . ISSN 0013-726X

\section{Corresponding author}

T. Yamaguchi, MD

Department of Gastroenterology

Chiba Cancer Center

666-2 Nitona-cho

Chuo-ku

Chiba City

Chiba

Japan

Fax: +81-43-2648175

tyamaguchi@chiba-cc.jp 